\title{
Distribution of Plasmodium spp. infection in asymptomatic carriers in perennial and low seasonal malaria transmission settings in West Africa
}

Constant G. N. Gbalégba ${ }^{1,2^{*}}$ (D), Hampâté Ba ${ }^{3}$, Kigbafori D. Silué ${ }^{2,4}$, Ousmane Ba ${ }^{3}$, Emmanuel Tia ${ }^{5}$, Mouhamadou Chouaibou ${ }^{2}$, Nathan T. Y. Tian-Bi ${ }^{2,4}$, Grégoire Y. Yapi ${ }^{5}$, Brama Koné2,6, Jürg Utzinger ${ }^{7,8}$ and Benjamin G. Koudou ${ }^{1,2,9}$

\begin{abstract}
Background: Since 2000, substantial progress has been made in reducing malaria worldwide. However, some countries in West Africa remain a hotspot for malaria with all age groups at risk. Asymptomatic carriers of Plasmodium spp. are important sources of infections for malaria vectors and thus contribute to the anchoring of the disease in favourable eco-epidemiological settings. The objective of this study was to assess the asymptomatic malaria case rates in Korhogo and Kaedi, two urban areas in northern Côte d'Ivoire and southern Mauritania, respectively.

Methods: Cross-sectional surveys were carried out during the rainy season in 2014 and the dry season in 2015 in both settings. During each season, 728 households were randomly selected and a household-based questionnaire was implemented to collect demographic and epidemiological data, including of malaria preventive methods used in communities. Finger-prick blood samples were obtained for biological examination using microscopy and rapid diagnostic tests (RDTs).

Results: Overall, 2672 households and 15858 consenting participants were surveyed. Plasmodium spp. infection was confirmed in 12.4\% $(n=832)$ and $0.3 \%(n=22)$ of the assessed individuals in Korhogo and Kaedi, respectively. In Korhogo, the prevalence of asymptomatic malaria was 10.5\% (95\% Cl: 9.7-11.2) as determined by microscopy and 9.3\% (95\% Cl: 8.6-10.0\%) when assessed by RDT. In Kaedi, asymptomatic malaria prevalence was 0.2\% (95\% Cl: 0.1-0.4\%) according to microscopy, while all RDTs performed were negative $(n=8372)$. In Korhogo, asymptomatic malaria infection was significantly associated with age and season, with higher risk within the 5-14 years-old, and during the rainy season. In Kaedi, the risk of asymptomatic malaria infection was associated with season only (higher during the dry season; crude $O R(c O R): 6.37,95 \%$ Cl: 1.87-21.63). P. falciparum was the predominant species identified in both study sites representing $99.2 \%(n=825)$ in Korhogo and $59.1 \%(n=13)$ in Kaedi. Gametocytes were observed only in Korhogo and only during the rainy season at $1.3 \%$ (95\% Cl: $0.7-2.4 \%)$.

(Continued on next page)
\end{abstract}

\footnotetext{
* Correspondence: gbalegba@yahoo.fr

'Unité de Formation et de Recherche Sciences de la Nature, Université

Nangui Abrogoua, 02 B.P. 801, Abidjan 02, Côte d'Ivoire

${ }^{2}$ Centre Suisse de Recherches Scientifiques en Côte d'Ivoire, 01 B.P. 1303,

Abidjan 01, Côte d'Ivoire

Full list of author information is available at the end of the article
} 


\begin{abstract}
(Continued from previous page)
Conclusions: Our findings show a low prevalence of clinical malaria episodes with a significant proportion of asymptomatic carriers in both urban areas. National policies for malaria infections are focused on treatment of symptomatic cases. Malaria control strategies should be designed for monitoring and managing malaria infections in asymptomatic carriers. Additional measures, including indoor residual spraying, effective use of long-lasting insecticidal nets is strongly needed to reduce the number of Plasmodium spp. infections in Korhogo and Kaedi.
\end{abstract}

Keywords: Plasmodium spp., Asymptomatic carriers, Urban area, Rapid diagnostic tests, Microscopy, Côte d'Ivoire, Mauritania, Korhogo, Kaedi

\section{Multilingual abstracts}

Please see Additional file 1 for translation of the abstract into the five official working languages of the United Nations.

\section{Background}

Malaria remains an important challenge for public health and economic development across the African continent. More than $85 \%$ of clinical malaria episodes and $90 \%$ of malaria- related deaths occur in sub-Saharan Africa, mainly in young children [1]. A large proportion of Plasmodium falciparum infections are asymptomatic in endemic countries [2-5]. In some of these countries, Plasmodium spp. asymptomatic carriers are not yet targeted by national intervention strategies, and hence represent a persistent pool for maintaining the parasite life cycle and transmission by the anopheline vector [3]. As additional challenge, vectors seem to be more susceptible to parasites from asymptomatic carriers than from symptomatic one's [6]. Consequently, the World Health Organization (WHO) suggests extending intervention strategies, including asymptomatic malaria cases, before planning for malaria elimination [1].

The commonly used criteria for defining asymptomatic malaria are parasite presence in peripheral thick blood films without symptoms and an axillary temperature less than $37.5^{\circ} \mathrm{C}$ [2, 7-9]. However, parasite prevalence estimations vary considerably according to age group and performance of diagnostic test used [10]. Indeed, the quality of microscopic diagnosis is not satisfying in many subSaharan African settings [10-12].

In Côte d'Ivoire, malaria transmission occurs throughout the year with a peak during the rainy season. Malaria is the first cause (43\%) of outpatient consultations in public health facilities [13]. The overall Plasmodium spp. prevalence rate through the country ranges from 64 to $75 \%$ [13]. In urban areas, malaria prevalence ranges from 30 to $40 \%$ [14]. However, the epidemiology of urban malaria in Côte d'Ivoire is not well documented, with a particular lack of information in the northern part of the country. Few studies pertaining to urban malaria were conducted in the South (Abidjan 2005, 2008), Southeast (Adzopé, in
2010) and the South-central (Taabo in 2016) of the country [15-18]. Data of the malaria burden in northern Côte d'Ivoire are more scarce. The most recent reports date back to 2003 and 2005 and identify the rural area of Korhogo district as hyper-endemic $[19,20]$. The lack of recent published epidemiological data from Korhogo may be partly due to two Ivorian civil wars that interrupted education and research programme from 2002 to 2011.

In Mauritania, malaria is currently the main cause of morbidity (22\%) and mortality (51\%) in health facilities $[21,22]$. The disease is the first cause of consultation and hospitalization in eight of thirteen regions of the country [22, 23]. An average of 200000 malaria cases per year have been reported by the health centre information system $[21,24]$ and malaria represents the third most frequent reason for outpatient consultations after respiratory infections and diarrhoea [23, 25]. Similar to Côte d'Ivoire, Mauritania suffers from a lack of data at regional and national level. Epidemiological data on malaria are rare and out of date, except those for the capital Nouakchott [21, 23]. In addition, most of the malaria cases in prior studies were identified by presumptive diagnostic [24-26]. Based on climatic and geographic features, Mauritania is divided in three epidemiological strata; from the South to the North we have (i) the Sahelien zone, located along the Senegal River; (ii) the Sahelo-saharan zone; and (iii) the Sahara zone, the largest one. In Kaedi, city that is located in the Sahelien zone and where P. falciparum is endemic, $25 \%$ of morbidity and $39 \%$ of mortality are caused by malaria according to the Ministry of Health [25]. A recent study conducted across these strata revealed that the Sahelo-sahara zone had the highest malaria burden, while the Sahelien zone had the lowest malaria prevalence [24]. However, the parasitological investigations were limited to 2-9 years-old children. Clinical data on asymptomatic Plasmodium carriers in Mauritania are even harder to find. In the Gorgol region, where Kaedi is the main city, malaria transmission is not well documented [23, 27]. Health authorities entertained hopes of reducing malaria morbidity and mortality by $75 \%$ by 2015 and potentially eliminate the disease from Mauritania [25]. In this context of low and seasonal malaria transmission, prevalence of asymptomatic infections needs 
to be clearly documented and appropriate interventions implemented for their adequate management.

Presently, in both countries, national malaria control programme strategies are based on (i) appropriate diagnosis and effective treatment of clinical cases; (ii) distribution of insecticide-treated nets (ITNs) free of charge among population, and (iii) intermittent preventive treatment (IPT) during pregnancy [13, 24]. However, larval control and indoor residual spraying (IRS) have not yet been implemented.

To enhance understanding of the epidemiology of asymptomatic malaria infection in these urban areas, two cross-sectional surveys were carried out for each site in two consecutive years (2014 and 2015) during the rainy and dry seasons.

\section{Methods}

\section{Study sites}

This study was conducted in urban areas of Korhogo in northern Côte d'Ivoire (N 09²7'41"; W 05 38'19") and
Kaedi in southern Mauritania (N 16 09'02"; W 13 $30^{\circ}$ $20^{\prime \prime}$ ) (Fig. 1). Korhogo is located at $663 \mathrm{~km}$ from Abidjan, the economic capital of Côte d'Ivoire. Its population was estimated at 286076 inhabitants in 2014 [28]. The average annual temperature is $27{ }^{\circ} \mathrm{C}$ and the average annual precipitation ranges from 1000 to $1300 \mathrm{~mm}$ [29]. The climate is Sudanese [30], characterized by one dry season (November-April) and one rainy season (May-October) with two rainfall peaks in June and September. The city has a water supply dam (flow $10^{6} \mathrm{~m}^{3}$ ) around which urban gardening has developed. Korhogo has a regional hospital with a bed capacity of 372 patients, a tuberculosis and blood transfusion centre.

Kaedi was already described elsewhere [31]. Briefly, the city is located approximately at $435 \mathrm{~km}$ from Nouakchott, the capital of Mauritania, and lies along the Senegal River that marks the border between Mauritania and Senegal. In 2013, its population was estimated at 118195 inhabitants. The average annual temperature is $29.5^{\circ} \mathrm{C}$ and the average annual rainfall ranges from 300 to $500 \mathrm{~mm}$. Kaedi is located within a Sahelian type climate zone with a wet

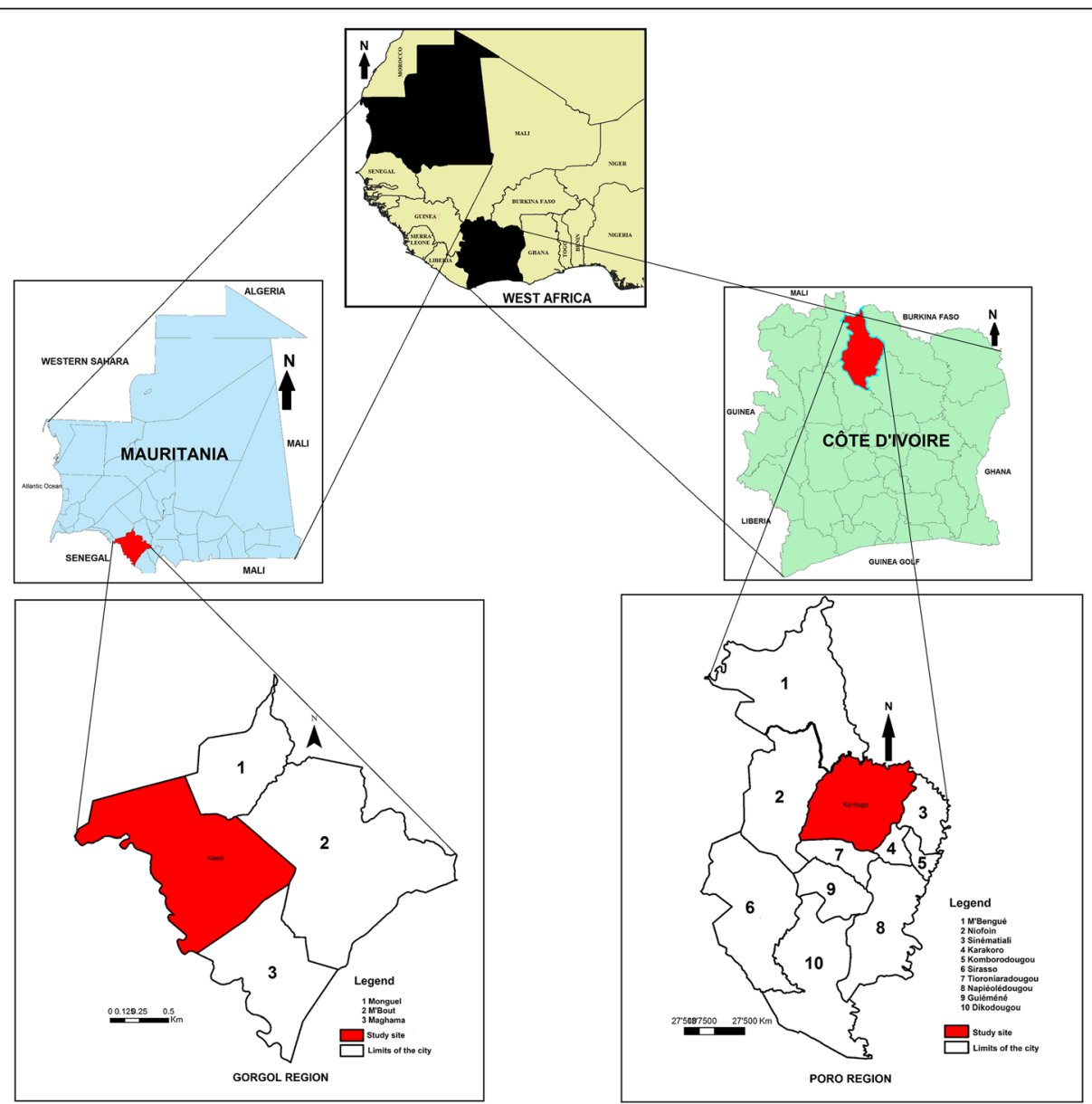

Fig. 1 Localization of study sites in Côte d'Ivoire and the Islamic Republic of Mauritania 
season from July to October, a 'cool' dry season from November to March and a 'hot' dry season from March to June. Kaedi has a regional hospital with a bed capacity of 120 patients.

The choice of the two urban settings is justified by the following reasons: (i) their respective positions to the North and South of the strip of the Sahel; (ii) because they were the study sites of a former project (Canadian International Development Research Centre [IDRC], grant no. 104270-013), which permit the establishment of research teams in both countries; (iii) the two study sites are secondary cities, even more vulnerable to the negative effects of climate change because of basic infrastructure (compared to capital cities) in most developing countries; (iv) and over the past $30-40$ years, West Africa region has been characterized by a decline of rainfall and the increasing of $1{ }^{\circ} \mathrm{C}$ in air temperature. In this context, high climatic variability conditions were observed in the two cities (i.e. intense periods of droughts [2007] and floods [2010, 2012]). Of note malaria is endemic and constitute public health problem in both cities.

\section{Study design, population and procedures}

Cross-sectional surveys were carried in July 2014 and March 2015 (in Korhogo) and in September 2014 and May 2015 (in Kaedi), during the rainy and the dry season, respectively.

For each survey, households were randomly selected from the 29 and 11 demographic zones in Korhogo and Kaedi, respectively. The number of households by demographic zones was proportionally allocated according to population size in each zone. The sample size $(n)$ was adjusted to 728 households obtained by using the following formula:

$n=\frac{\delta^{2} \times P(1-P) \times C}{i^{2}}$ where $\delta$, standard deviation (1.96); $P$, the expected prevalence (35\%) based on [32]; $i$, precision or margin of error (5\%) and $C=2$, correction coefficient.

In each site, the objective of the study was discussed with the selected healds of household. For each household head or their representative, written informed consent was obtained and a questionnaire was administered in order to obtain demographic information of all household members as well as malaria preventive measures used in the household. Thick and thin blood films and rapid diagnostic tests (RDTs) were systematically performed for all consenting and assenting participants across all age groups. In addition, weight and axillary temperature were recorded. In each household, clinical malaria cases based on RDT positive + fever (because microscopy readings were not yet available) were treated with artemisinin-based combination therapy (ACT), according to country guidelines. In Côte d'Ivoire, clinical cases received artesunate and amodiaquine according to age. Treatments were performed by physician/nurses from the regional hospital of Korhogo. In Mauritania, clinical cases were not treated as all RDT were negative.

\section{Laboratory evaluation}

Based on the predominant Plasmodium species encountered at each study site, malaria Ag P.f (Standard Diagnostics (SD) Inc.; Yongin, Republic of Korea) was used in Korhogo. Diagnostic tests based on histidine-rich protein 2 are specific to $P$. falciparum. The Pf/HRP2-based RTDs are recommended by the national malaria control program and used at national level in Côte d'Ivoire. In Kaedi, Ag P.f/Pan (SD, Inc.; Yongin, Republic of Korea) was applied for detection of Plasmodium spp. These tests are recommended by the national malaria control programme in Mauritania for simultaneous detection and differentiation of HRP2 and pLDH (Plasmodium lactate dehydrogenase) specific to other Plasmodium species in human specimens. RDT results were obtained within 15 min during the household visit. Finger prick blood samples were taken from study participants and labelled with the same participant code. Thin blood films were fixed with methanol. Thick and thin blood films were stained with $10 \%$ Giemsa and examined under a microscope at $\times 100$ magnitude with immersion oil. Microscope readings were performed at the "Centre Suisse de Recherches Scientifiques en Côte d'Ivoire" and the "Institut National de Recherche en Santé Publique, Nouakchott" by experienced technicians under the supervision of a parasitologist. Thin blood films were examined for Plasmodium species identification and asexual stage counted according to 200 or 500 leucocytes. Parasite density was expressed as the number of asexual parasites per $\mu \mathrm{l}$ of blood [33]. A quality control was made for $10 \%$ randomly selected slides by a senior technician. Slides with conflicting results were re-read by a third technician and the results discussed until a consensus was reached.

\section{Data analysis}

Data were entered with Epidata (EpiData Association; Odense, Denmark) and analyzed using Stata version 14.1 (Stata Corporation; College Station, TX, USA). Prevalence of infection was estimated as proportion and compared using Pearson $\chi^{2}$ test or Fisher's exact test, as appropriate. Data summary was done using descriptive statistics. Parasite density was normalized by $\log (x+1)$ for a 0 count and to obtain similar variances between groups before using parametric tests. ANOVA one way or $t$-test was used to check for any statistical difference in the geometric means of parasite density between sex, age- 
groups and season and a 95\% CI was used to measure the strength of association between prevalence or parasite density infection status and variables. Fever was defined as having an axillary body temperature that is equal to or greater than $37.5{ }^{\circ} \mathrm{C}$ and clinical malaria was defined as association of fever and the presence of asexual parasites of Plasmodium spp. in the blood film [34]. Age was stratified into six groups: $<1 ; 1-4 ; 5-9 ; 10-14$; 15-19 and $\geq 20$ years, according WHO guidelines [35]. Plasmodium spp. infection intensity was categorised by three groups: $1-500,501-5000$ and $>5000$ parasites $/ \mu$ of blood. Bivariate analyses were used to evaluate association between estimates prevalence and sex, age and season. Binary logistic regression was employed to assess the risk factors associated with Plasmodium spp. infection. Variables significant at $P$-value of 0.25 in the univariate logistic regression were selected for multivariate logistic regression analysis model. For all statistical tests, a 5\% level of significance level was used.

\section{Results}

Characteristics of the study participants

Information on the season and demographic characteristics of the study participants are summarized in Table 1. In Korhogo, a total of 1259 households were included in the study (Fig. 2) with a total of 9144 individuals of which 6693 (73.2\%) had a complete data set. Most of study participants $(n=3006 / 6693 ; 76.1 \%)$ were illiterate $(n=1518 ; 38.4 \%)$ or had attended primary school $(n=1488 ; 37.7 \%)$. In Kaedi, a total of 1413 households were included in the study (Fig. 2) with a total of 12 488 individuals of which 9165 (73.2\%) had complete data. The majority of the individuals included in the study were illiterate $(n=3561,40.3 \%)$, or had primary school level $(n=2901 ; 32.8 \%)$.

The rate of long-lasting insecticidal nets (LLINs) possession in selected households of the two study sites was 93.2\% (1308/1403) in Korhogo and 95.7\% (1391/1453) in Kaedi.

Table 1 Demographic characteristics of the sample populations in Korhogo, northern Côte d'Ivoire and Kaedi southern Mauritania, 2014/2015

\begin{tabular}{|c|c|c|c|c|}
\hline \multirow[t]{2}{*}{ Variable } & \multicolumn{2}{|l|}{ Korhogo } & \multicolumn{2}{|l|}{ Kaedi } \\
\hline & Frequency (\%) & $P$-value & Frequency (\%) & $P$-value \\
\hline Participants with complete data & $6693(73.2)$ & & $9165(73.4)$ & \\
\hline \multicolumn{5}{|l|}{ Sex } \\
\hline Male & $2801(41.8)$ & $<0.001$ & $3612(39.4)$ & $<0.001$ \\
\hline Female & $3892(58.2)$ & & $5553(60.6)$ & \\
\hline Sex ratio (male:female) & 0.72 & & 0.65 & \\
\hline \multicolumn{5}{|l|}{ Age group (year) } \\
\hline$<1$ & $223(3.3)$ & $<0.001$ & $436(4.8)$ & $<0.001$ \\
\hline $1-4$ & $925(13.8)$ & & $1115(12.2)$ & \\
\hline $5-9$ & $1201(18.0)$ & & $1908(20.8)$ & \\
\hline $10-14$ & $962(14.4)$ & & $2201(24.0)$ & \\
\hline $15-19$ & $710(10.6)$ & & $1997(21.8)$ & \\
\hline$\geq 20$ & $2672(39.9)$ & & $1508(16.5)$ & \\
\hline \multicolumn{5}{|l|}{ Education level } \\
\hline Illiterate & $1518(38.5)$ & $<0.001$ & $3561(40.3)$ & $<0.001$ \\
\hline Koranic school & $238(6.0)$ & & $1188(13.4)$ & \\
\hline Primary school & $1488(37.7)$ & & $2901(32.8)$ & \\
\hline Secondary school & $628(15.9)$ & & $1070(12.1)$ & \\
\hline Higher academic level & $75(1.9)$ & & $126(1.4)$ & \\
\hline \multicolumn{5}{|l|}{ Possession of LLINS } \\
\hline Yes & $1308(93.2)$ & $<0.001$ & $1391(95.7)$ & $<0.001$ \\
\hline No & $95(6.8)$ & & $62(4.3)$ & \\
\hline \multicolumn{5}{|l|}{ Season } \\
\hline Rainy & $3266(48.8)$ & $<0.001$ & $4748(51.8)$ & $<0.001$ \\
\hline Dry & $3427(51.2)$ & & 4417 (48.2) & \\
\hline
\end{tabular}




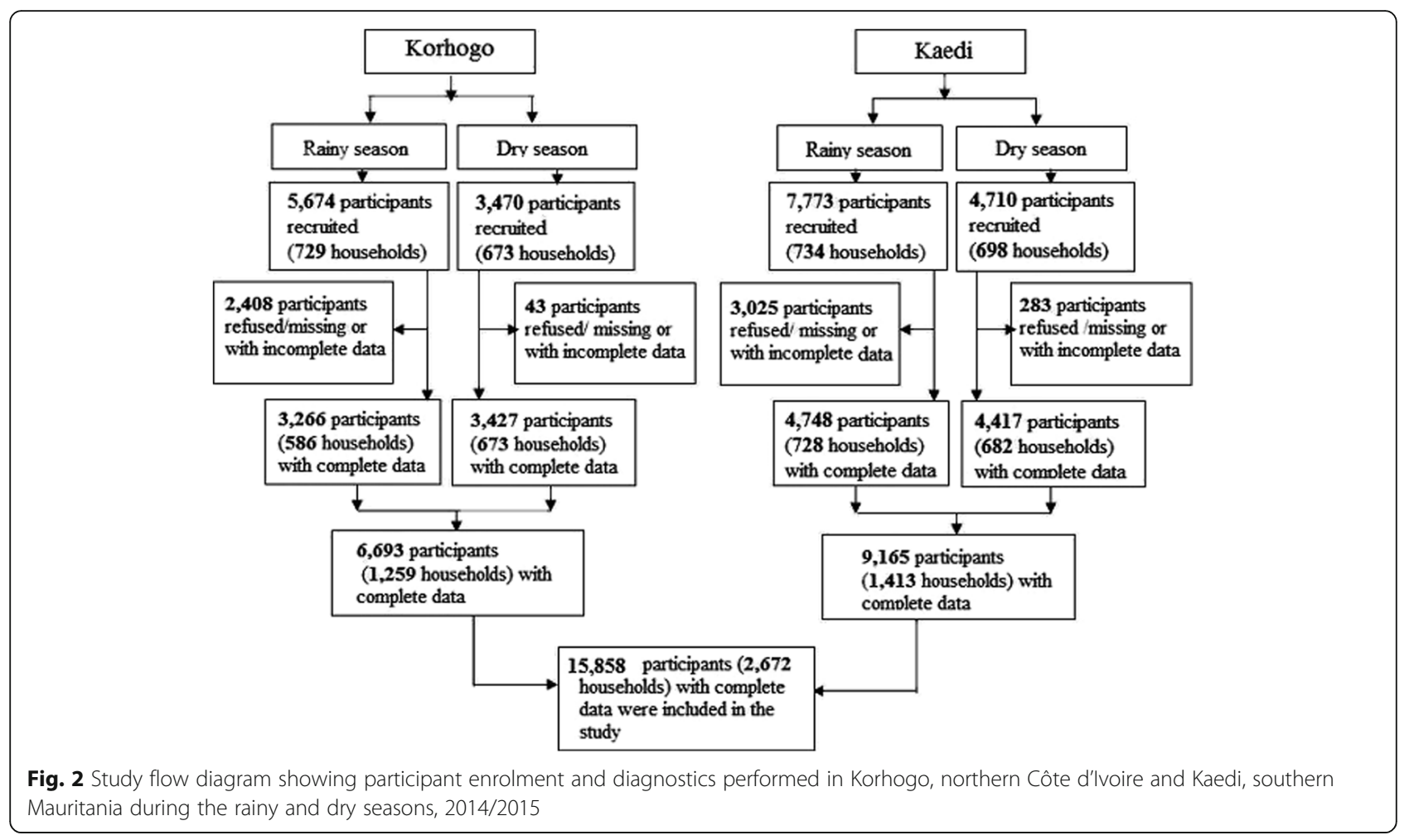

\section{Plasmodium spp. infection prevalence and parasite density}

The prevalence of Plasmodium spp. infection and parasite density according to season and demographic characteristics are presented in Table 2.

In Korhogo, 6693 microscopy diagnoses on thick blood films and an equivalent number of RDTs was carried out during the two seasons in parallel. The overall Plasmodium parasite rate in both seasons as confirmed by microscopy was $12.4 \%$ (95\% CI: $11.7-13.2 \%$ ), while the rate covered with the RDT was 10.5\% (95\% CI: 9.8-11.3\%). The parasite index was $17.4 \%$ (95\% CI: 16.1-18.7\%) for the rainy season and $7.7 \%$ (95\% CI: 6.9-8.7\%) for the dry season. P. falciparum prevalence (RDT positive) was $11.7 \%$ (95\% CI: 10.7-12.9\%) and 9.3\% (95\% CI: 8.4-10.4\%), during the rainy and dry season, respectively. Plasmodium spp. infection was significantly associated with age group, fever status and the season (Table 2). Moreover, the prevalence of infection peaked in age group 10-14 years using each of the diagnostic methods. Febrile participants had significantly higher (15.4\%; 95\% CI: 12.6-18.7\%) Plasmodium spp. prevalence compared to non-febrile participants (11.4\%; 95\% CI: $10.6-12.3 \%) \quad(P=0.006)$. Similarly, the prevalence of Plasmodium spp. was significantly higher during the rainy season compared to the dry season for both diagnostic methods $(P<0.001$ for both). The overall geometric mean of parasite density (GMPD) among infected participants was 220 parasites/ $\mu \mathrm{l}$ (95\% CI: 199-244). Parasite density was sex, age, fever status and season dependant (Table 2). Indeed, the GMPD of male (256 parasites/ $\mu$ l, 95\% CI: 223-295) was higher compared to female (195 parasites/ $\mu$ l, 95\% CI: 171-223). The GMPD was relatively high in $1-4$ years-old children (275 parasites $/ \mu$ l, 95\% CI: 205-375) and low in adult participants (178 parasites $/ \mu$ l, 95\% CI: 152-210), similarly among the febrile (329 parasites/ $\mu$ l, 95\% CI: 229-487) compared with nonfebrile participants (208 parasites/ $\mu \mathrm{l}, 95 \%$ CI: 188-232). The rainy season had the highest GMPD (236 parasites/ $\mu \mathrm{l}, 95 \%$ CI: 210-264). P. falciparum, P. malariae and mixed infections accounted for $99.2 \%$ (825/832), 0.2\% (2/832) and $0.6 \%(5 / 832)$ of the total cases, respectively. No P. ovale infection was observed in any of the examined blood samples. Eleven individuals $(11 / 825 ; 1.3 \%)$ carried gametocytes during the rainy season (Table 3). The prevalence rate of $P$. falciparum gametocytes was found to be similar in terms of sex, age and fever status. No gametocytes were found in individuals aged less than 1 year and between 15 and 19 years-old.

In Kaedi, 9165 thick and thin blood films and an equivalent number of RDTs (SD Bioline-Antigen Pf/ Pan) were performed during both seasons. All RDTs were negative. The prevalence of Plasmodium spp. infection, as assessed by microscopy across both seasons, was 0.2\% (95\% CI: $0.1-0.4 \%$ ) (Table 2). This prevalence was similar in all age groups. In addition, no infants under 1 year of age were infected. Plasmodium spp. infection was similar in febrile and non-febrile participants. However, the prevalence of infection was higher in the 
Table 2 Plasmodium spp. prevalence by microscopy and parasite density among study participants in Korhogo, northern Côte d'Ivoire and Kaedi southern Mauritania, 2014/2015, stratified by sex, age, fever status and season

\begin{tabular}{|c|c|c|c|c|c|c|}
\hline \multirow[t]{2}{*}{ Variable } & \multicolumn{3}{|l|}{ Korhogo } & \multicolumn{3}{|l|}{ Kaedi } \\
\hline & $n$ (Positive) & Prevalence $(95 \%$ Cl) & GMPD $(95 \%$ Ch) & $n$ (Positive) & Prevalence $(95 \%$ Cl) & GMPD $(95 \%$ Cl) \\
\hline Overall & $6693(832)$ & $12.4(11.7-13.2)$ & $220(199-244)$ & $9165(22)$ & $0.2(0.1-0.4)$ & $229(153-357)$ \\
\hline \multicolumn{7}{|l|}{ Sex } \\
\hline Male & $2801(370)$ & $13.2(12.0-14.5)$ & $256(223-295)^{\mathrm{b} *}$ & $3612(8)$ & $0.2(0.1-0.4)$ & $199(93-482)^{b}$ \\
\hline Female & $3892(462)$ & $11.9(10.9-12.9)$ & $195(171-223)$ & $5553(14)$ & $0.4(0.1-0.4)$ & 249 (144-449) \\
\hline \multicolumn{7}{|c|}{ Age group (year) } \\
\hline$<1$ & $223(22)$ & $9.9(6.6-14.6)^{*}$ & $158(96-275)^{C *}$ & $175(0)$ & & \\
\hline $1-4$ & $925(111)$ & $12.0(10.1-14.3)$ & $275(205-375)$ & $1376(7)$ & $0.5(0.2-1.0)$ & $275(99-897)^{c}$ \\
\hline $5-9$ & $1201(197)$ & $16.4(14.4-18.6)$ & $261(212-326)$ & $1908(3)$ & $0.2(0.0-0.4)$ & $180(56-787)$ \\
\hline $10-14$ & $962(160)$ & $16.6(14.4-19.1)$ & $223(178-280)$ & $1301(2)$ & $0.2(0.0-0.6)$ & $651(400-857)$ \\
\hline $15-19$ & $710(89)$ & $12.5(10.3-15.2)$ & $227(170-307)$ & $900(1)$ & $0.1(0.0-0.6)$ & $436(29-465)$ \\
\hline$\geq 20$ & $2672(253)$ & $9.5(8.4-10.6)$ & $178(152-210)$ & $3505(9)$ & $0.3(0.1-0.5)$ & 165 (97-292) \\
\hline \multicolumn{7}{|l|}{ Fever $^{a}$} \\
\hline Yes & $538(83)$ & $15.4(12.6-18.7)^{\mathrm{d} *}$ & $329(229-487)^{\mathrm{b} *}$ & $522(1)$ & $0.2(0.0-1.1)$ & $3497(2072-4284)^{b}$ \\
\hline No & $5890(673)$ & $11.4(10.6-12.3)$ & $208(188-232)$ & $8372(21)$ & $0.3(0.2-0.4)$ & $205(143-304)$ \\
\hline \multicolumn{7}{|l|}{ Season } \\
\hline Rainy & $3266(567)$ & $17.4(16.1-18.7)^{d *}$ & $236(210-264)^{\mathrm{b} *}$ & $4748(3)$ & $0.1(0.0-0.2)^{d *}$ & $320(32-608)^{\mathrm{b} *}$ \\
\hline Dry & $3427(265)$ & $7.7(6.9-8.7)$ & $191(160-229)$ & 4417 (19) & $0.4(0.3-0.7)$ & $218(146-336)$ \\
\hline
\end{tabular}

${ }^{a}$ Out of study participants, 265 (4\%) and 271 (3\%) did not have axillary temperature data in Korhogo and Kaedi, respectively; ${ }^{\mathrm{b}}$ Obtained by Student's $t$-test between groups, 'Obtained by ANOVA between groups; ${ }^{d}$ Obtained by Pearson's X2 test; * $P<0.05$; CI Confidence interval; GMPD Geometric mean of parasite density (parasites/ $\mu \mathrm{l}) ; n$ Number examined

dry season $(0.4 \%, 95 \% C I$ : $0.3-0.7 \%)$ compared to the wet season $(0.1 \%$, 95\% CI: $0.0-0.2 \%),\left(\chi^{2}=12.90, P<0.001\right)$. The overall GMPD among infected participants was 229 parasites/ $\mu \mathrm{l}$ (95\% CI: 153-357). The GMPD was relatively high in 10-14 years-old children (651 parasites/ $\mu \mathrm{l}, 95 \%$ CI: 400-857) and low in adult participants (165 parasites/ $\mu$ l, 95\% CI: 97-292). Season was significantly associated with parasite density, as assessed by bivariate analysis (Table 2). The GMPD was higher in the dry season than the rainy season (OR: 6.82, 95\% CI: 2.02-23.10) with a more than six times higher odds to carry a parasite in this season. Sex, age and fever status were not significantly associated with parasite density. Three species of Plasmodium were reported: $P$. falciparum $(n=13,56.5 \%), P$. malariae $(n=2,8.7 \%)$ and $P$. vivax ( $n=1,4.3 \%$ ). In subsequent analyses, the only case of $P$. vivax was not included due to absence of sex and age information. In addition, in 7 infections (30.4\%), Plasmodium spp. could not be identified due to the deterioration of the thin blood film.

\section{Prevalence, parasite density and factors associated with asymptomatic Plasmodium spp. infection}

The prevalence, parasite density and the factors associated with asymptomatic Plasmodium spp. infection according to setting, season and demographic characteristics are presented in Table 4.
In Korhogo, the overall prevalence of asymptomatic malaria was $10.5 \%$ (95\% CI: 9.7-11.2\%). Females were more affected with asymptomatic infection than males but the difference was not statistically significant $\left(\chi^{2}=3.15, \quad P=0.076\right)$. Asymptomatic infection was observed in all age groups. Children aged 5-9 years (14.1\%, 95\% CI: $12.1-16.2 \%)$ and $10-14$ years (13.8\%, 95\% CI: 13.1-16.3\%) were the most likely to be infected, while infants less than 1 year were found to be the least infected (7.6\%, 95\% CI: 4.4-12.0\%) (Fig. 3). Moreover, it was found that the prevalence of asymptomatic infection was higher during the rainy season compared to the dry season $\left(\chi^{2}=86.97, P=0.001\right)$.

The GMPD was 208 parasites/ $\mu$ l of blood (95\% CI: 188-232). Parasite density was associated with sex, age and season. Indeed, it was higher in males (GMPD: 249 parasites/ $\mu$ l, 95\% CI: 214-292) than in females (GMPD: 182 parasites/ $\mu \mathrm{l}, 95 \% \mathrm{CI}$ : 158-210), ( $t=2.21, P=0.013)$. Children aged 5-9 years presented the highest GMPD (264 parasites/ $\mu \mathrm{l}, 95 \%$ CI: 210-339) (Fig. 3). The GMPD was also higher in the rainy season (212 parasites/ $\mu \mathrm{l}$, 95\% CI: 188-241) compared to the dry season (201 parasites/ $\mu \mathrm{l}, 95 \%$ CI: 166-246) $(t=-11.99, P<0.001)$.

In Kaedi the overall prevalence of asymptomatic infection was $0.2 \%(95 \%$ CI: $0.1-0.3 \%)$ with males and females having the same probability of being infected with 
Table 3 Plasmodium falciparum gametocytes among the study population, stratified by sex, age, parasite density and season in Korhogo, northern Côte d'Ivoire, 2014/2015

\begin{tabular}{|c|c|c|c|c|c|}
\hline \multirow[t]{2}{*}{ Variable } & \multicolumn{3}{|c|}{ P. falciparum gametocytes } & \multirow[b]{2}{*}{$x^{2}$} & \multirow[b]{2}{*}{$P$-value } \\
\hline & $n$ & Positive & Prevalence $(95 \%$ Cl) & & \\
\hline Overall & 825 & 11 & $1.3(0.7-2.4)$ & & \\
\hline \multicolumn{6}{|l|}{ Sex } \\
\hline Male & 365 & 5 & $1.4(0.5-3.2)$ & 11.3 & 0.255 \\
\hline Female & 460 & 6 & $1.3(0.5-2.8)$ & & \\
\hline \multicolumn{6}{|c|}{ Age group (year) } \\
\hline$<1$ & 21 & 0 & - & 47.23 & 0.381 \\
\hline $1-4$ & 110 & 2 & $1.8(0.2-6.4)$ & & \\
\hline $5-9$ & 197 & 3 & $1.5(0.3-4.4)$ & & \\
\hline $10-14$ & 156 & 3 & $1.9(0.4-5.5)$ & & \\
\hline $15-19$ & 89 & 0 & - & & \\
\hline$\geq 20$ & 252 & 3 & $1.2(0.3-3.4)$ & & \\
\hline \multicolumn{6}{|l|}{ Fever $^{a}$} \\
\hline Yes & 82 & 1 & $1.2(0.0-6.6)$ & 11.95 & 0.153 \\
\hline No & 668 & 10 & $1.5(0.7-2.7)$ & & \\
\hline \multicolumn{6}{|c|}{ PD (parasites/ $\mu$ l of blood) } \\
\hline $1-500$ & 577 & 12 & $2.1(1.1-3.6)$ & 3.19 & 0.202 \\
\hline $501-5000$ & 207 & 1 & $0.5(0.0-2.7)$ & & \\
\hline$>5000$ & 41 & 0 & - & & \\
\hline \multicolumn{6}{|l|}{ Season } \\
\hline Rainy & 560 & 11 & $1.9(1.0-3.5)$ & 13.66 & 0.135 \\
\hline Dry & 265 & 0 & - & & \\
\hline
\end{tabular}

${ }^{a}$ Of the participants examined for $P$. falciparum gametocytes, 75 (10.6\%) did not have axillary temperature data. $\mathrm{Cl}$ Confidence interval, $P D$ Parasite density, $n$ Number examined

asymptomatic infection $\left(\chi^{2}=0.30, P=0.580\right)$. All age groups were affected by asymptomatic malaria, except infants under 1 year old. The prevalence of asymptomatic infection was statistically similar in all age groups, with children aged 1-4 years being the most infected (Fig. 3).

Asymptomatic infections were significantly associated with season and was more likely to occur in the dry season compared to the wet season $\left(\chi^{2}=11.60, P=0.001\right)$.

The overall GMPD was 208 parasites/ $\mu$ l of blood (95\% CI: 144-307). Females had a higher GMPD (249 parasites/ $\mu \mathrm{l}, 95 \%$ CI: 146-449) compared to males (146 parasites/ $\mu \mathrm{l}, 95 \%$ CI: 109-197); however, the difference was not statistically significant. Children aged $10-14$ years had the highest GMPD (651 parasites/ $\mu$ l, 95\% CI: 400-857) (Fig. 3). The GMPD was higher in the rainy season (323 parasites/ $\mu \mathrm{l}, 95 \% \mathrm{CI}$ : 144-455) compared to the dry season (193 parasites/ $\mu$ l, $95 \%$ CI: $140-272$ ), $(t=-3.45 ; P=0.003)$.

In the univariate analysis, sex, age group and season were significantly associated with the prevalence of asymptomatic Plasmodium spp. infection in Korhogo at
$P$-value $<0.25$. However, in the multivariable logistic regression analysis, age group 5-9 years (adjusted $O R$ ), [aOR]: 0.51, 95\% CI: 0.30-0.87), 10-14 years (aOR: 0.50, 95\% CI: $0.30-0.87)$ and the rainy season $(\mathrm{aOR}: 0.45$, 95\% CI: 0.38-0.53) were significantly associated with the prevalence of asymptomatic Plasmodium spp. infection.

In Kaedi, by contrast, only the season was associated with asymptomatic Plasmodium spp. infection, this reason did not allow us to perform a multivariate analysis. In univariate analysis, the risk of asymptomatic Plasmodium spp. infection was 6.36 times (crude $O R$ [cOR]: 1.87-21.63) higher during the dry season, compared to the rainy season.

\section{Discussion}

The present study assessed the prevalence of Plasmodium spp. with a focus on the distribution of Plasmodium spp. infection in asymptomatic carriers from urban areas of Korhogo in Côte d'Ivoire and Kaedi in Mauritania.

The prevalence of Plasmodium infection observed in Korhogo (12.4\%) was generally low compared to other reports in urban settings in Côte d'Ivoire [15, 18, 36]. A particularly low prevalence was observed in participants under 1 year and between 1 and 4 years of age, which is likely to be due to the protective effect of maternal antibodies against malaria antigens [37-39]. As the protective >effect of maternal antibodies decreases with age, the observed low prevalence over this age group may also be related to the integrated management of less than 5 yearsold patients. Efforts have been made to improved health system in the management of diseases in this age group.

The low prevalence of malaria infection observed in Kaedi $(0.2 \%, 22 / 9165)$ may be partly attributed to the divers Global Fund-supported intervention strategies implemented in this area, such as LLINs, IPT for pregnant women and immediate treatment with ACTs. In a recent study conducted in Rosso, a city located along the Senegal River, localised in the Sahelian zone, Ouldabdallahi and colleagues [40] reported a higher prevalence rate. In this city, $2.5 \%$ of the 1431 febrile paediatric and adult patients screened were malaria-positive. Indeed, the zone bordering the Senegal River has a general reputation to be a high P. falciparum setting [24]. Nevertheless, malaria prevalence was low in the Sahelian zone, whilst the highest burden was observed in the SaheloSaharan zone.

A recent study conducted in three strata in Mauritania [24] showed that the Sahelian zone had the lowest malaria prevalence $(14 / 1056 ; 1.3 \%)$, compared to the other strata. The situation was shown to be similar at the opposite site of the River, where the number of new malaria cases was low since 1990 [41, 42].

School-aged children (i.e. 5-14 years of age) in Korhogo and preschool-aged children $(<5$ years $)$ in Kaedi presented 
Table 4 Prevalence by microscopy, parasite density and factors associated with asymptomatic Plasmodium spp. infection among study participants in Korhogo, northern Côte d'Ivoire and in Kaedi, southern Mauritania, 2014/2015

\begin{tabular}{|c|c|c|c|c|c|c|c|c|c|}
\hline \multirow[t]{2}{*}{ Variable } & \multicolumn{5}{|l|}{ Korhogo } & \multicolumn{4}{|l|}{ Kaedi } \\
\hline & $n$ (Positive) & $\begin{array}{l}\text { Prevalence } \\
(95 \% \text { Cl) }\end{array}$ & $\begin{array}{l}\text { Univariate } \\
\text { cOR }(95 \% \text { CI) }\end{array}$ & $\begin{array}{l}\text { Multivariate } \\
\mathrm{aOR}(95 \% \mathrm{Cl})\end{array}$ & $\begin{array}{l}\text { GMPD } \\
(95 \% C l)\end{array}$ & $n$ (Positive) & $\begin{array}{l}\text { Prevalence } \\
(95 \% \mathrm{Cl})\end{array}$ & $\begin{array}{l}\text { Univariate } \\
\text { cOR }(95 \% \text { Cl) }\end{array}$ & $\begin{array}{l}\text { GMPD } \\
(95 \% C D)\end{array}$ \\
\hline Overall & $6428(673)$ & $10.5(9.7-11.2)$ & & & $208(188-232)$ & 8894 (21) & $0.2(0.1-0.3)$ & & $208(144-307)$ \\
\hline \multicolumn{10}{|l|}{ Sex } \\
\hline Male & 3744 (302) & $8.1(7.2-9.0)$ & 1.00 & 1.00 & $249(214-292)^{a *}$ & $3494(7)$ & $0.2(0.1-0.4)$ & 1.00 & $146(109-197)^{a}$ \\
\hline Female & $2684(371)$ & $13.8(12.5-15.2)$ & $1.16(0.98-1.36)^{d}$ & $1.06(0.90-1.26)$ & $182(158-210)$ & $5400(14)$ & $0.3(0.1-0.4)$ & $1.29(0.52-3.20)$ & $249(146-449)$ \\
\hline \multicolumn{10}{|c|}{ Age group (year) } \\
\hline$<1$ & $211(16)$ & $7.6(4.4-12.0)^{c *}$ & 1.00 & 1.00 & $113(69-193)^{\mathrm{b} *}$ & $167(0)$ & - & - & - \\
\hline $1-4$ & $887(84)$ & $9.5(7.6-11.6)$ & $0.77(0.44-1.35)$ & $0.79(0.45-1.40)$ & $254(182-360)$ & $1323(6)$ & $0.5(0.2-1.0)$ & $170(0.60-4.80)$ & $197(91-482)^{\mathrm{b}}$ \\
\hline $5-9$ & $1157(163)$ & $14.1(12.1-16.2)$ & $0.49(0.29-0.84)^{d}$ & $0.51(0.30-0.87)^{*}$ & $264(210-339)$ & $1853(3)$ & $0.2(0.0-0.5)$ & $0.61(0.16-2.26)$ & $180(57-787)$ \\
\hline $10-14$ & 917 (127) & $13.8(13.1-16.3)$ & $0.49(0.28-0.85)^{d}$ & $0.50(0.30-0.87)^{*}$ & $190(152-236)$ & $1265(2)$ & $0.2(0.0-0.6)$ & $0.60(0.13-2.79)$ & $651(400-857)$ \\
\hline $15-19$ & $684(73)$ & $10.7(8.5-13.2)$ & $0.69(0.39-1.22)^{d}$ & $0.71(0.40-1.27)$ & $229(166-323)$ & $873(1)$ & $0.1(0.0-0.6)$ & $0.43(0.05-3.43$ & $436(29-465)$ \\
\hline$\geq 20$ & $2572(210)$ & $8.2(7.1-9.3)$ & $0.94(0.55-1.60)$ & $0.99(0.58-1.70)$ & 175 (147-208) & $3413(9)$ & $0.3(0.1-0.5)$ & 1.00 & 166 (98-295) \\
\hline \multicolumn{10}{|l|}{ Season } \\
\hline Rainy & $3167(446)$ & $14.1(12.9-15.3)^{c *}$ & $0.45(0.38-0.54)^{d}$ & $0.45(0.38-0.53)^{*}$ & $212(188-241)^{\mathrm{a} *}$ & $4633(3)$ & $0.1(0.0-0.2)^{c *}$ & 1.00 & $323(144-455)^{\mathrm{a} *}$ \\
\hline Dry & $3261(227)$ & $7.0(6.1-7.9)$ & 1.00 & 1.00 & $201(166-246)$ & $4261(18)$ & $0.4(0.3-0.7)$ & $6.36(1.87-21.63)^{d}$ & $193(140-272)$ \\
\hline
\end{tabular}

${ }^{a}$ Obtained by Student's $t$-test between groups; ${ }^{b}$ obtained by ANOVA between groups; ${ }^{\mathrm{c}}$ obtained by Pearson's $\times 2$ test between groups, ${ }^{\mathrm{d}}$ Significant at $P$-value $<0.25$; aOR Adjusted odds ratio, COR Crude odds ratio, CI Confidence interval, GMPD Geometric mean of parasitaemia, $n$ Number examined; * ${ }^{*}$ ignificant at $P$-value $<0.05$

the highest asymptomatic malaria prevalence. It was previously shown that teenagers sleep under bed nets less frequently than the preschool-aged children. Those asymptomatic teenagers raise many issues because they are unknown carriers of the parasite and these reservoirs contribute in maintaining the parasite lifecycle, as documented in malaria-endemic communities [37, 43]. However, African teenagers often show clinical immunity that prevents them to express malaria symptoms in spite of their regular exposure to the parasite during seasons of high-transmission [37]. Prevention and treatment programme rarely target school aged-children as opposed to younger children that leave an important intervention gap. School-aged children need to be included in any comprehensive malaria prevention strategy.

In the current study, parasitaemia increased with age in children aged 1-5 years, and declined thereafter, suggesting a certain immune protection during the childhood obtained at an early age. This explains why children falling into this age category were found to be asymptomatic most of the times.

The proportion of Plasmodium spp. positive febrile participants was $15.4 \%$ and 0, 2\% in Korhogo and Kaedi, respectively. The prevalence of Plasmodium spp. in feverish participants in Korhogo was higher than in those with no fever. Indeed, the majority of fever cases in both sites was not due to malaria parasitaemia. The association between malaria parasitaemia and fever has been convincingly documented in endemic areas [44-46]. In urban areas, fevers are not necessarily due to malaria; hence, treatment of fever as malaria based only on a presumptive diagnostic could be considered as wastage of resources and lead to sub-optimal or wrong treatment. Unfortunately, malaria presumptive treatment is common in health facilities in the study sites and elsewhere in the two countries $[13,22]$.

The prevalence of asymptomatic infection in Korhogo was $10.5 \%$ (ranging from $8.3 \%$ to $12.3 \%$ ). This prevalence rate was similar to the prevalence of asymptomatic malaria cases documented in a mountainous district in Ghana (11.9\%) [47]. This finding showns a lower percentage than the one reported from urban setting elsewhere in Côte d'Ivoire $[18,36]$ but was higher than the prevalence reported in urban areas of Dakar (ranging from 0\% to 7.5\%) [48] and Kenya (ranging from $1.3 \%$ to $8.1 \%$ ) [49]. In Kaedi, the prevalence of asymptomatic infection was $0.2 \%$ (ranging from $0.1 \%$ to $0.3 \%$ ) and the majority of participants with a positive blood film (21/22; 95\%) were asymptomatic. Therefore, this prevalence is low compared with that obtained in a study conducted among schoolaged children $(n=1040,0.9 \%)$ in Trarza region in the Sahelian zone [40]. Asymptomatic infection cases were likely to be detected more by microscopy, mainly in Kaedi, compared to RDTs. RDTs are often less sensitive in low parasitaemia $(<100$ parasites/ $\mu$ l of blood). In addition, mutation can occur in parasite strain. Pf-HRP2 mutations reported in Central and South America and Asia [50, 51] have yet to be documented in our study areas. These mutations can have an impact on RDT sensitivity.

In areas where malaria transmission is high, regular infection with Plasmodium results in partial immunity and favours asymptomatic parasite carriers (APCs) [2, 48, 

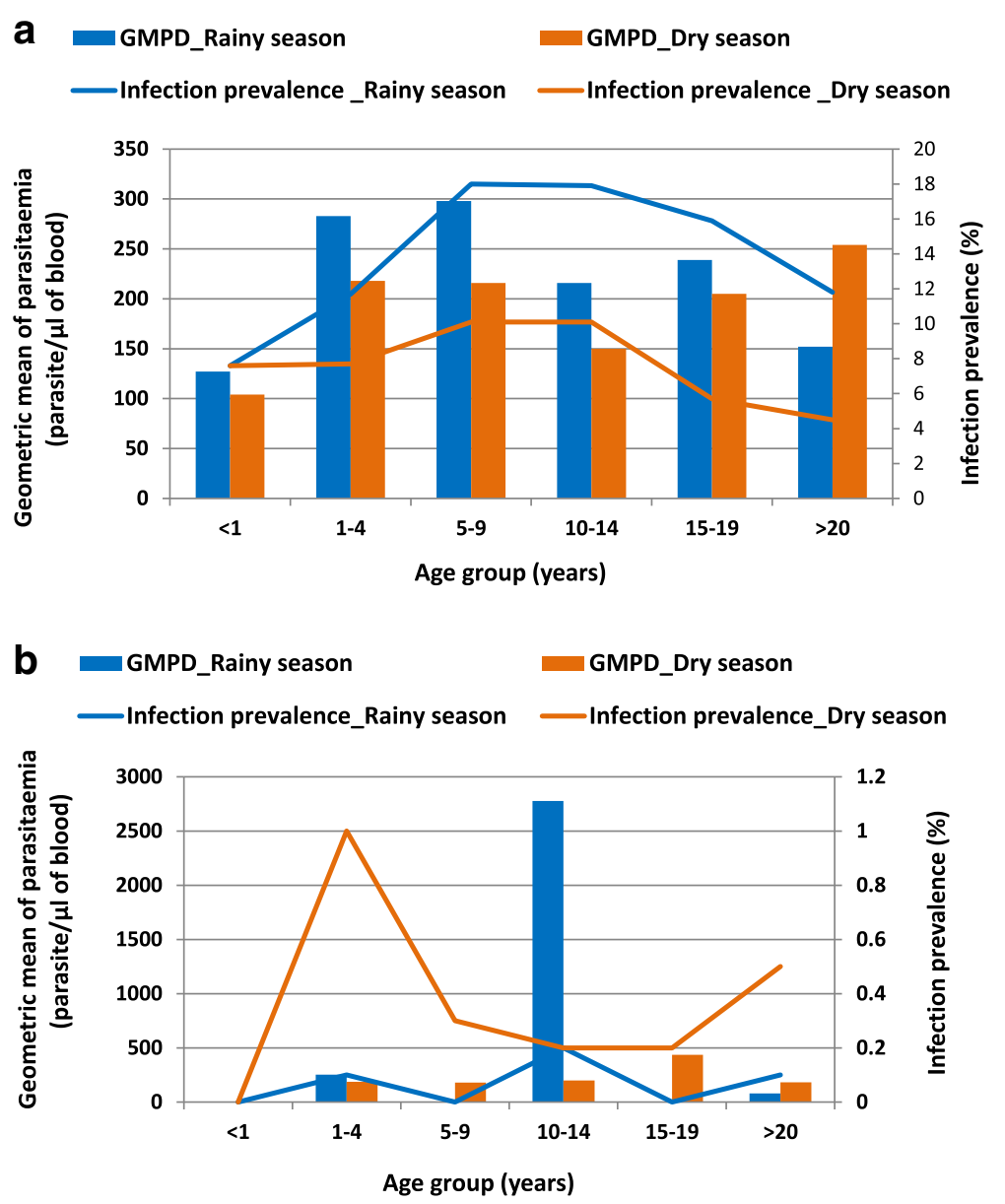

Fig. 3 Age-specific prevalence of asymptomatic Plasmodium spp. infection and geometric mean parasitaemia within the study participant stratified by season (a) in Korhogo (northern Côte d'Ivoire) and (b) in Kaedi (southern Mauritania), 2014/2015

52]. These APCs represent parasites reservoir and contribute to disease distribution by infection of anopheline mosquitoes in some period [53-55]. These periods could be the rainy season in Korhogo, and specifically, two months after the irrigation of the rice fields in Kaedi. Therefore, the treatment of APCs in endemic areas may reduce the rate of clinical cases [56].

In the two sites surveyed, malaria infection follows a seasonal variation. However, while in Korhogo malaria was found at the highest prevalence during the rainy season, the opposite was observed in Kaedi where the prevalence of infection was higher during the dry season. In Korhogo, the high malaria prevalence during the rainy season is likely to be due to the abundance of Anopheles mosquitoes during this period. The rainfall creates more productive breeding sites to renew vectors populations, and hence, malaria transmission intensifies. Moreover, during the rainy period, higher amounts of gametocyte carriers are generated. The observations made in Kaedi do not fit with this common pattern and are different to a report from a southern area of
Mauritania [24], where malaria prevalence was found to be higher during the rainy season, compared with the 'cool' dry season. This contradictory result could be due to the period of field investigations and the low abundance of malaria vectors during this period. A previous study [57] recorded a prevalence rate of $16.6 \%$ in AprilMay 2003 in Nouakchott, corresponding to the dry season, however, the study participant were febrile when they were recruited. A recent study conducted in Kaedi, during the dry season, revealed the absence of Plasmodium parasitaemia [26]. However, only children aged between 6 and 59 months were screened. Socio-economic environment and geographic characteristics of a town seem to influence both malaria transmission and severity. Also, vectors densities and sporozoite rates influence entomological inoculation rate.

In Korhogo, two Plasmodium species were found (i.e. P. falciparum and P. malariae) out of the three species previously reported from Côte d'Ivoire [18, 36]. In Kaedi, three species of Plasmodium were observed during our study (i.e. P. falciparum, $P$. malariae and $P$. vivax) as 
previously reported from Mauritania [21, 24, 58] and the Sahelian zone along the Senegal River in particular. However, only one case of $P$. vivax was found. This species is mainly found in Nouakchott because of a high density of Duffy-positive $P$. vivax-susceptible individuals among the population [21, 23]. A recent study conducted in the Sahelian zone did not find any $P$. vivax infection among 1050 children screened [24]. Our single $P$. vivax identified case may be related to people movement from Nouakchott, $P$. vivax endemic area in Mauritania. P. falciparum was the dominant species in Korhogo and in Kaedi, which is in line with previous studies in both countries $[18,21,26,36]$ and in West Africa $[47,59]$. Yet, WHO indicates in the most recent malaria country profile map for Mauritania, that the Gorgol region is free of $P$. falciparum cases [60]. Data generated from this study can greatly contribute to update regional epidemiological data over years.

Our study has several limitations that should be taken into consideration when interpreting the results. Firstly, the current level of APCs proportion, especially in Kaedi, may be underestimated. Indeed, in low transmission area, parasite density seemed low; therefore, high sensibility diagnostic methods like PCR and loop-mediated isothermal DNA amplification are needed to identify malaria cases that are not detectable via microscopy $[55,61]$. Furthermore, because of time limitations, we did not follow-up APCs to determine the time-period until they become symptomatic after the initial diagnosis. Such information is essential to guide appropriate treatment strategies.

\section{Conclusion}

The study shows that in the urban areas of Korhogo, in northern Côte d'Ivoire and Kaedi, in southern Mauritania, malaria prevalence is low with non-negligible proportions of APCs. We highlight also the implication of school-aged children and adults as Plasmodium spp. reservoirs and thus contributing greatly to the anchoring of malaria in favourable eco-epidemiological zones. Ours results have implications for malaria control programme in Côte d'Ivoire and Mauritania, which, currently, do not include APCs in intervention strategies likewise of school-aged children and adults. Hence, the authors recommend further investigations placing emphasis on APCs in each study country in order to design and implement appropriate surveillance and control measures.

\section{Additional file}

Additional file 1: Multilingual abstracts in the five official working languages of the United Nations. (PDF $736 \mathrm{~kb}$ )

\section{Abbreviations}

APC: Asymptomatic parasite carrier; Cl: Confidence interval; GMPD: Geometric mean of parasite density; IPT: Intermittent preventive treatment; IRS: Indoor residual spraying; LLIN: Long-lasting insecticidal net; OR: Odd ratio; PD: Parasite density; RDT: Rapid diagnostic test; SD: Standard diagnostic; WHO: World Health Organization

\section{Acknowledgements}

We thank Korhogo's and Kaedi's communities, health workers and the regional and departmental health directorate. The authors are grateful to Mary Simwango and Vera Mwangi for their contribution during the preparation of this manuscript. We would particularly like to thank the field investigators and the microscopists. The authors also thank the other team members for their assistance during data collection. We thank Drs. Jasmina Saric, Loukou Kouassi and Alassane Ouattara for their editorial support.

\section{Funding}

This project received financial support from the UNICEF/UNDP/World BankWHO Special Programme for Research and Training in Tropical Diseases (TDR) and the Canadian International Development Research Centre (IDRC), grant no. NB20283 (Dr. Koné Brama). The funders had no role in study design, data collection and analyses, decision to publish, or preparation of the manuscript.

\section{Availability of data and materials}

The datasets supporting the conclusions of this article are included within the article. Raw data used for analysis of the study are available from the corresponding author on reasonable request.

\section{Authors' contributions}

$B K, K D S, H B, O B, E T, M C, N T Y T B, G Y Y, B G K$ and JU designed the study; CGNG, $\mathrm{HB}, \mathrm{OB}$ and KDS executed the study. CGNG analysed the data and wrote the first draft of the manuscript. All authors read and approved the final revision of the manuscript.

\section{Ethics approval and consent to participate}

In Côte d'Ivoire, the National Ethics Committee cleared the research protocol (reference $n^{\circ} 10$ 056/MSHP/CNER-dkn, dated 29 May 2013). In Mauritania, the scientific committee of the Faculty of Medicine (University of Nouakchott), acting as a national ethic committee, cleared the research protocol (reference $n^{\circ}$ 042/USTM/FM, dated 23 May 2013). In addition, local authorities in the study sites were informed about the objectives, procedures and benefits of the study. Household heads or their representatives were asked to register and to give written informed consent prior to participation. However, if the participant was illiterate, his/her thumb print with the signature of a witness was obtained. All participants diagnosed malaria positive by any of the diagnostic tools were treated with anti-malarial drugs according to national malaria programme guidelines. Information obtained from each study participant was kept confidential.

Consent for publication Not applicable.

\section{Competing interests}

The authors declare that they have no competing interests.

\section{Author details}

${ }^{1}$ Unité de Formation et de Recherche Sciences de la Nature, Université Nangui Abrogoua, 02 B.P. 801, Abidjan 02, Côte d'Ivoire. ${ }^{2}$ Centre Suisse de Recherches Scientifiques en Côte d'Ivoire, 01 B.P. 1303, Abidjan 01, Côte d'Ivoire. ${ }^{3}$ Laboratoire de Parasitologie - Mycologie, Institut National de Recherches en Santé Publique, B.P. 695, Nouakchott, Mauritania. ${ }^{4}$ Unité de Formation et de Recherche Biosciences, Université Félix Houphouët-Boigny, 22 B.P. 582, Abidjan 22, Côte d'Ivoire. ${ }^{5}$ Centre d'Entomologie Médicale et Vétérinaire, Université Alassane Ouattara, 27 B.P. 529, Abidjan 27, Côte d'Ivoire. 'Université Péléforo Gon Coulibaly, B.P. 1328, Korhogo, Côte d'Ivoire. ${ }^{7}$ Swiss Tropical and Public Health Institute, P.O. Box, CH- 4002 Basel, Switzerland. ${ }^{8}$ University of Basel, P.O. Box, CH-4003 Basel, Switzerland. ${ }^{9}$ Centre for Neglected Tropical Diseases, Liverpool School of Tropical Medicine, Pembroke Place, Liverpool L3 5QA, UK. 


\section{Received: 17 September 2017 Accepted: 24 March 2018} Published online: 25 April 2018

\section{References}

1. WHO. World Malaria Report 2016. Geneva: World Health Organization. http://eproofing.springer.com/journals_v2/index.php?token= F4vmvuzUWNsffEeeSSNE-pnXFQUjN3tEquOvfFiyiYc.

2. Males S, Gaye O, Garcia A. Long-term asymptomatic carriage of Plasmodium falciparum protects from malaria attacks: a prospective study among Senegalese children. Clin Infect Dis. 2008;46:516-22.

3. Kimbi KH, Ajeagah UH, Keka CF, Lum E, Nyabeyeu NH, Tonga FC, et al. Asymptomatic malaria in school children and evaluation of the performance characteristics of the Partec Cyscope ${ }^{\circledast}$ in the Mount Cameroon region. J Bacteriol Parasitol. 2012;3:7.

4. Singh R, Godson II, Singh S, Singh BR, Isyaku TN, Ebere VU. High prevalence of asymptomatic malaria in apparently healthy schoolchildren in Aliero, Kebbi state, Nigeria. J Vector Borne Dis. 2014;51:128-32.

5. Nzobo JB, Ngasala EB, Kihamia MC. Prevalence of asymptomatic malaria infection and use of different malaria control measures among primary school children in Morogoro municipality, Tanzania. Malar J. 2015;14:491.

6. Gouagna $\mathrm{CL}$, Okech AB, Karibu EW, Killeen FG, Obare P, Ombonya S, et al. Infectivity of Plasmodium falciparum gametocytes in patients attending rural health centres in western Kenya. East Afr Med J. 2003;80:627-34.

7. Leoratti FM, Durlacher RR, Lacerda MV, Alecrim MG, Ferreira AW, Sanchez MC, et al. Pattern of humoral immune response to Plasmodium falciparum blood stages in individuals presenting different clinical expressions of malaria. Malar J. 2008;7:186.

8. Duarte J, Deshpande P, Guiyedi V, Mecheri S, Fesel C, Cazenave PA, et al. Total and functional parasite specific IgE responses in Plasmodium falciparum-infected patients exhibiting different clinical status. Malar J. 2007;6:1-10.

9. De Mast Q, Syafruddin D, Keijmel S, Riekerink TO, Deky O, Asih PB, et al. Increased serum hepcidin and alteration in blood iron parameters associated with asymptomatic P. falciparum and P. vivax malaria. Haematology. 2010;95:1068-74.

10. Nankabirwa IJ, Yeka A, Arinaitwe E, Kigozi R, Drakeley C, Kamya MR, et al. Estimating malaria parasite prevalence from community surveys in Uganga: a comparison of microscopy, rapid diagnostic tests and polymerase chain reaction. Malar J. 2015;14:528

11. Bisoffi Z, Gobbi F, Buonfrate D. Jef van den E. Diagnosis of malaria infection with or without disease. Mediterr J Hematol Infect Dis. 2012;4:e2012036.

12. Azikiwe CCA, Ifezulike CC, Siminialayi IM, Amazu LU, Enye JC, Nwakwunite OE. A comparative laboratory diagnosis of malaria: microscopy versus rapid diagnostic test kits. Asian Pac J Trop Biomed. 2012;2:307-10.

13. PNLP: Programme National de Lutte Contre le Paludisme en Côte d'Ivoire. Plan stratégique national de lutte contre le paludisme 2012-2015 (période replanifiée 2014-2017. Approche stratifiée de mise à l'échelle des interventions de lutte contre le paludisme en Côte d'Ivoire et consolidation des acquis. Abidjan: Ministère de la Santé et l'Hygiène Publique; p. 149.

14. PNLP, 2005. Rapport annuel sur la situation du paludisme. Programme National de Lutte contre le Paludisme, Ministère de la santé et de l'Hygiène Publique. République de Côte d'Ivoire, p. 163.

15. Wang JS, Lengeler C, Smith AT, Vounatsou P, Cissé G, Tanner M. Rapid urban malaria appraisal (RUMA) III: epidemiology of urban malaria in the municipality of Yopougon (Abidjan). Malar J. 2006;5:29.

16. Assoumou A, Adoubryn KD, Aboum KS, Kouadio-Yapo CG, Ouhon J. Portage symptomatique et asymptomatique de Plasmodium falciparum chez les enfants de 6 mois à 6 ans à l'hôpital general d'Abobo (Abidjan, Côte d'Ivoire). Bull Soc Pathol Exot. 2008;100(1):50-3.

17. Assi SB, Ouattara L, Adja AM, Bla KB, Tchiekoi NB, Lingué N. Epidemiology of malaria in urban area (Adzopé city, Côte d'Ivoire), Am-Euras. J Sci Res. 2010; 5:94-100.

18. Bassa KF, Outtara M, Silué KD, Adiossan LG, Baikoro N, Kone S, et al. Epidemiology of malaria in Taabo health and demographic surveillance system, south-central Côte d'Ivoire. Malar J. 2016;15:9.

19. Henry MC, Rogier C, Nzeyimana I, Assi SB, Dossou-Yovo J, Audibert M, et al. Inland valley rice production systemsand malaria infection and disease in the savannah of Côte d'Ivoire. Tropical Med Int Health. 2003:8:449-58.

20. Henry MC, Assi SB, Rogier C, Dossou-Yovo J, Chandre F, Guillet P, et al. Protective efficacy of lambda-cyhalothrin treated nets in Anopheles gambiae pyrethroid resistance areas of Côte d'Ivoire. Am J Trop Med Hyg. 2005;73:859-64.
21. Salam MOS, Bosco LK, Ouldaballahi M, Lekweiry KM, Konaté L, Faye O, et al. Malaria-associated morbidity during the rainy season in Saharan and Sahelian zones in Mauritania. Acta Trop. 2015;152:1-7.

22. Lekweiry MK, Salem MSOA, Basco KL, Briolant S, Hafid J, Boukhary SMOA. Malaria in Mauritania: retrospective and prospective overview. Malar J. 2015;14:100.

23. Lekweiry MK, Abdallahi OM, Bâ H, Arnathau C, Durant P, Trape JF, et al. Preliminary study of malaria incidence in Nouakchott, Mauritania. Malar J. 2009:8:92

24. Moukah OM, Ba O, Ba H, Khairy OLM, Faye O, Bogreau H, et al. Malaria in three epidemiological strata in Mauritania. Malar J. 2016;15:204.

25. Malaria Control Unit. Mauritanian Ministry of Health. Plan stratégique de lutte contre le paludisme 2011-2015. In: Nouakchott; 2011.

26. Touray S, Bâ H, Bâ O, Koïta M, Salem OAM, Keïta M, et al. Absence of dry season Plasmodium parasitaemia, but high rates of reported acute respiratory infection and diarrhoea in preschool-aged children in Kaédi, southern Mauritania. Parasit Vectors. 2012;5:193.

27. Ba H, Duffy CW, Ahouidi AD, Deh YB, Diallo MY, Tandia A, et al. Widespread distribution of Plasmodium vivax malaria in Mauritania on the interface of the Maghreb and West Africa. Malar J. 2016;15:80.

28. RPGH. Recensement Général de la Population et de I'Habitat, Côte d'Ivoire. Rapport du secrétariat technique permanent du comité technique du RGPH, (2014). p. 26. http://www.ins.ci/n/Resultats\%20globaux.pdf. Accessed 24 Oct 2015.

29. Goula BTA, Konan B, Brou YT, Savané I, Fadika V, Srohourou B. Estimation des pluies exceptionnelles journalières en zone tropicale : cas de la Côte d'Ivoire par comparaison des lois Log normale et de Gumbel. Hydrol Sci J. 2007:52:49-67.

30. Jourda JP, Saley BM, Djagoua EV, Kouamé KJ, Biémi J Razack M. Utilisation des données ETM+ de Landsat et d'un SIG pour l'évaluation du potentiel en eau souterraine dans le milieu fissuré précambrien de la région de Korhogo (Nord de la Côte d'Ivoire): Approche par analyse multicritère et test de validation. Télédetection, 2005:5:339-357.

31. Gbalégba NGC, Silué DK, Ba O, Ba H, Tian Bi TYN, Yapi YG, et al. Prevalence and seasonal transmission of Schistosoma haematobium infection among school-aged children in Kaedi town, southern Mauritania. Parasit Vectors. 2017;10:353.

32. Raso G, Schur N, Utzinger J, Koudou BG, Tchicaya ES, Rhoner F, et al. Mapping malaria risk among children in Côte d'Ivoire using Bayesian geo-statistical models. Malar J. 2012;11:160.

33. Moody A. Rapid diagnostic tests for malaria parasites. Clin Microbiol Rev. 2002;15:66-78.

34. Keiser J, Utzinger J, Caldas de Castro M, Smith AT, Tanner M, Singer HB. Urbanization in sub-Saharan Africa and implication for malaria control. Am J Trop Med Hyg. 2004;71(Suppl 2):118-27.

35. WHO. Terminology of malaria and malaria eradication. Geneva: World Health Organization; 2016. http://apps.who.int/iris/bitstream/10665/208815/ 1/WHO_HTM_GMP_2016.6_eng.pdf.

36. Assi SB, Henry MC, Rogier C, Dossou- YJ, Audibert M, Mathonnat J, et al. Inland valley rice production systems and malaria infection and disease in the forest region of western Côte d'Ivoire. Malar J. 2013;12:233.

37. IA MG. Epidemiology, malaria and pregnancy. Am J Trop Med Hyg. 1984;33: $517-25$.

38. Riley EM, Wagner GE, Akanmori BD, Koram KA. Do maternally acquired antibodies protect infants from malaria infection? Parasite Immunol. 2001;23:51-9.

39. D'Alessandro U, Ubben D, Hamed K, Ceesay JS, Okebe J, Taal M, et al. Malaria in infants aged less than six months - is it an area of unmet medical need? Malar J. 2012;11:400

40. Ouldabdallahi M, Ouldbezeid M, Dieye M, Yacine B, Faye O. Etude de la part du paludisme chez les consultants fébriles et des indices plasmodiques chez les écoliers dans la région du Trarza, République Islamique de Mauritanie. Bull Soc Pathol Exot. 2011;104:288-90.

41. Faye O, Fontenille D, Hervé JP, Diack PA, Diallo S, Mouchet J. Le paludisme en zone sahélienne du Sénégal. 1. Donnés entomologiques sur la transmission. Ann Soc Belg Med Trop. 1993;73:21-30

42. Faye $\mathrm{O}$, Gaye $\mathrm{O}$, Konaté L, Molez JF, Feller-Dansokho E, Hervé JP. Prévision et prévention des épidémies de paludisme dans la vallée du fleuve Sénégal. Santé. 1998:8:347-52.

43. Ferreira UM, Castro CM. Challenges for malaria elimination in Brazil. Malar J. 2016;15:284.

44. Trape JF, Peelman P, Morault-Peelman B. Criteria for diagnosing clinical malaria among a semi-immune population exposed to intense and perennial transmission. Trans R Soc Trop Med Hyg. 1985;79:435-42. 
45. Bouvier P, Rougemont A, Breslow N, et al. Seasonality and malaria in West African village: does high parasite density predictfever incidence? Am J Epidemiol. 1997;145:850-7.

46. Dicko A, Mantel C, Kouriba B, Sagara I, Thera AM, Doumbia S, et al. Season, fever prevalence and pyrogenic threshold for malaria disease definition in an endemic area of Mali. Trop Med Int Health. 2005;10(6):550-6.

47. Owusu DAE, Buabeng V, Dadzie S, Brown AC, Grobusch PM, Mens P. Characterstics of asymptomatic Plasmodium spp. parasitaemia in KwahuMpraeso, a malaria endemic mountainous district in Ghana, West Africa. Malar J. 2016;15:38

48. Diallo A, Ndam NT, Moussiliou A, Dos Santos S, Ndonky A, Borderon M, et al. Asymptomatic carriage of Plasmodium in urban Dakar: the risk of malaria should not be understimated. PLoS One. 2012;7:e31100.

49. John CC, McHugh MM, Moormann AM, Sumba PO, Ofulla AV. Low prevalence of Plasmodium flaciparum infection among asymptomatic individuals in a highland area of Kenya. Trans R Soc Trop Med Hyg. 2005;99:780-6.

50. Kumar N, Pande V, Bhatt RM, Shah NK, Mishra N, Srivastava B, et al. Genetic deletion of HRP2 and HRP3 in Indian Plasmodium falciparum population and false negative malaria rapid diagnostic test. Acta Trop. 2013;125:119-21.

51. Viana RGM, Okoth AS, Silva-Flannery L, Barbosa LDR, De Oliveira MA, Goldman IF, et al. Histidine-rich protein 2 (pfhrp2) and pfhrp3 gene deletions in Plasmodium falciparum isolates from select sites in Brazil and Bolivia. PLoS One. 2017;12(3):e0171150.

52. Staalsoe $T$, Hviid $L$. The role of variant-specific immunity in asymptomatic malaria infections: maintaining a fine balance. Parasitol Today. 1998;14:177-8.

53. Alves FP, Gil LH, Marrelli MT, Ribolla PE, Camargo EP, Pereira-da-Silva LH. Asymptomatic carriers of Plasmodium spp. as infection source for malaria vector mosquitoes in the Brazilian Amazon. J Med Entomol. 2005:42:777-9.

54. Nath MJ, Bora AK, Yadav K, Talukdar PK, Dhiman S, Baruah I, et al. Prioritizing areas for malaria control using geographical information system in an endemic district of Assam. India. Public Health. 2003;127:572-80.

55. Zoghi S, Mehrizi AA, Raeisi A, Haghdoost AA, Turki H, Kahanali AA, et al. Survey for symptomatic malaria cases in low transmission settings of Iran under elimination programme. Malar J. 2012;11:126.

56. Tada SM, Ferreira FMGR, Katsuragawa HT, Martha DCR, Costa NJD, Albrecht $L$, et al. Asymptomatic infection with Plasmodium falciparum and Plasmodium vivax in the Brazilian Amazon Basin: to treat or not to treat? Mem Inst Oswaldo Cruz. 2012;107:621-9.

57. Cortes H, Morillas-Marquez F, Valero A. Malaria in Mauritania: the first cases of malaria endemic to Nouakchott. Trop Med Int Health. 2003:8:297-300.

58. Ouldabdallahi M, Ouldbezeid M, Lemrabot MA, Ouldelvally A, Ouldkhairi ML, Dalw B, et al. Etude de la morbidité et espèce de Plasmodium dans les differentes zones géo-climatiques de la Mauritanie. Bull Soc Pathol Exot. 2015;108:112-6.

59. Mweigwa J, Okebe J, Affara M, Tanna LDG, Nwakanma D, Janha O, et al. Ongoing malaria transmission in the Gambia despite high coverage of control interventions: a nationwide cross-sectional survey. Malar J. 2015;14:314

60. WHO: World Malaria Report; 2015. http://www.who.int/malaria/publications/ country-profiles/profile_mrt_en.pdf. Accessed 28 May 2016.

61. Baliraine FN, Afrane YA, Amenya DA, Bonizzoni M, Menge DM, Zhou G, et al. High prevalence of asymptomatic Plasmodium falciparum infections in a highland area of western Kenya: a cohort study. J Infect Dis. 2009;200:66-74

\section{Submit your next manuscript to BioMed Central and we will help you at every step:}

- We accept pre-submission inquiries

- Our selector tool helps you to find the most relevant journal

- We provide round the clock customer support

- Convenient online submission

- Thorough peer review

- Inclusion in PubMed and all major indexing services

- Maximum visibility for your research

Submit your manuscript at www.biomedcentral.com/submit
Biomed Central 